\title{
Residência de Medicina de Família e Comunidade: uma Estratégia de Qualificação
}

\author{
Community and Family Medical Residency: a \\ Qualifying Strategy
}

\author{
Verônica Said de Castro ${ }^{I}$ \\ Silvia Maria Nóbrega-Therrien II
}

\section{PALAVRAS-CHAVE \\ - Avaliação educacional. \\ - Programa Saúde da Família. \\ - Residência médica. \\ - Internato e residência}

\section{KEYWORDS}

- Educational evaluation.

- Family Health Program.

- Medical residency.

- Internship and residency

Recebido em: 19/02/2008

Reencaminhado em: 20/06/2008

Aprovado em: 28/09/2008

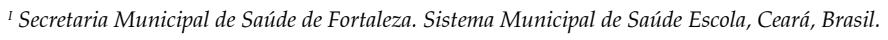

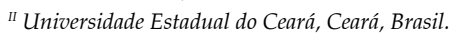

Este artigo mostra os resultados de uma pesquisa sobre a avaliação do curso de Residência de Medicina de Família e Comunidade da Secretaria Municipal de Saúde de Fortaleza, uma estratégia de qualificação para os profissionais do Programa Saúde da Família, com base na opinião dos alunos/residentes concluintes do segundo ano do curso. O processo avaliativo teve como foco a estrutura e o conteúdo das aulas teóricas, e, principalmente, os ganhos obtidos pelos alunos em conhecimentos, habilidades e atitudes, numa perspectiva de correção de rumos. Utilizou-se uma abordagem qualitativa, na modalidade estudo de caso, e o instrumento de coleta de dados foi um questionário com questões abertas. Os sujeitos totalizaram 20 alunos/residentes. Para a análise dos dados utilizou-se a técnica de análise de conteúdo, modalidade temática. Os resultados mostraram que os alunos estavam conseguindo adquirir as principais competências necessárias a um médico de família, mas é preciso realizar ajustes em termos de conteúdo do programa e das condições das unidades de saúde, campos de prática dos alunos/residentes.

This article provides the results of a study on the evaluation of the course in Family and Community Medical Residency under the Municipal Health Department in Fortaleza, Ceará State, Brazil, as a strategy for qualifying health professionals for the Family Health Program, based on the opinion of students/residents at the end of the course's second year. The evaluation process focused on the structure and content of the theoretical classes and especially the gains obtained by students in their knowledge, skills, and attitudes, from a perspective of adjusting the course's approach. A qualitative case-study design was adopted, using an open-ended questionnaire as the data collection instrument. The sample included 20 students/residents. Data were analyzed with content analysis, using a thematic modality. According to the findings, the students were able to acquire the main skills needed by family physicians, but adjustments proved necessary in terms of the program content and conditions in the municipal health clinics, which serve as the practical training areas for the students/residents. 


\section{INTRODUÇÃO}

Como proposta para estruturar a atenção primária em nosso país, o Ministério da Saúde lançou, em 1994, o Programa Saúde da Família (PSF). A essência desta proposta repousava na mudança do modelo convencional de atenção, focado na doença, para a atenção no indivíduo, na família e no meio em que ela vive. Trata-se de uma estratégia que elege, como nos refere Pelliano ${ }^{1}$, o estabelecimento de vínculos e de corresponsabilidades entre a equipe de saúde e a comunidade assistida. Essa estratégia/programa se expandiu rapidamente, uma vez que dados referentes a março de 2007 confirmam 27.146 equipes de Saúde da Família implantadas em 5.110 municípios². Fortaleza conta atualmente com 300 equipes implantadas nas unidades básicas do município.

O PSF foi concebido para servir como porta de entrada de um sistema hierarquizado e regionalizado de saúde, tendo território definido com uma população delimitada sob a sua responsabilidade, de forma a intervir sobre os fatores de risco aos quais à comunidade está exposta e prestar assistência integral, permanente e de qualidade, incluindo a realização de atividades de educação e promoção da saúde ${ }^{3}$.

Diante da importância que essa estratégia está assumindo na organização da atenção à saúde da população brasileira, um questionamento nos surgiu de imediato: estamos formando profissionais com o perfil requerido para trabalhar com esse novo modelo? Se levarmos em conta o fato de que a maioria dos cursos de graduação na área da saúde, principalmente os de Medicina, forma profissionais tendo como cenários de aprendizagem, notadamente, ambientes hospitalares e como prática dominante a atenção individual e especializada, cabe questionar se os profissionais egressos desses cursos estariam devidamente preparados para atuar na estratégia Saúde da Família, numa visão integral de indivíduos, família e comunidade. Amoretti ${ }^{4}$ corrobora esse pensamento quando descreve o perfil predominante do profissional médico dos dias atuais:

ser essencialmente positivista, com enfoque biologicista e utilitário, centrado na sua especialidade, predisposto à utilização de novas tecnologias, com tendência a medicalizar o processo saúde-doença, marcadamente individualista, resistente a trabalhar em equipe, crítico do SUS, etc. (p. 140)

Machado ${ }^{5}$, em seu estudo sobre o perfil dos médicos e enfermeiros do PSF no Brasil, mostrou que a quase totalidade desses profissionais expressou a necessidade de maior aprimoramento técnico-científico para atuarem no programa, salientando a importância dos processos de qualificação.
Diante dessas constatações, o sistema de saúde encontrase frente ao desafio de criar estratégias educacionais efetivas para formar um profissional com determinado perfil para atuar na atenção primária e/ou requalificar os que já estão inseridos nas unidades básicas de saúde, com a finalidade de ofertar serviços de qualidade à população.

Nessa perspectiva, a formação desse novo médico está ligada diretamente às mudanças dos currículos das universidades para adequar o ensino às competências necessárias ao profissional que hoje inicia sua prática profissional e tem como principal campo de oferta de trabalho a Estratégia Saúde da Família (ESF).

O Ministério da Saúde, por meio dos Polos de Educação Permanente, incentivou a oferta de cursos de especialização em saúde da família, notadamente teóricos. Esses cursos introduziram melhorias para a assistência às comunidades, contudo, por se restringirem ao estudo em sala de aula, distanciado da prática real, os resultados parecem não ter conseguido provocar mudanças significativas para a reversão do modelo assistencial focado na doença e sem vínculos com a população assistida.

Nesse contexto, os programas de residências multiprofissionais em saúde da família e residência de medicina de família e comunidade surgem como proposta de qualificação para os profissionais que já atuam no PSF, com abordagem metodológica capaz de induzir as desejadas mudanças na prática médica. Segundo Gualberto ${ }^{6}$, a residência médica constitui a mais perfeita modalidade de aperfeiçoamento e especialização em Medicina.

Em consonância com a visão de $\mathrm{Mendes}^{7}$, entendemos que a perspectiva de quem aprende é fundamental na prática avaliativa, pois suas observações podem subsidiar os professores na correção de rumos do processo formativo. Nessa mesma linha de pensamento, Rodrigues ${ }^{8}$ sustenta que "as avaliações provocam mudanças internas e externas que só ocorrem substancialmente quando se considera a participação dos atoressujeitos responsáveis diretos pelas ações desenvolvidas". Nessa perspectiva e considerando que é consenso entre os gestores a necessidade de melhor qualificação de profissionais médicos para atuarem na ESF, este artigo tem por objetivo apresentar os resultados de uma pesquisa que avaliou o curso de RMFC da Secretaria Municipal de Saúde de Fortaleza (SMSF) em termos de estrutura, recursos metodológicos, conteúdo e os ganhos em competências na opinião dos participantes do curso.

\section{O PROGRAMA DE RESIDÊNCIA DE MEDICINA DE FAMÍLIA E COMUNIDADE (RMFC) DA SECRETARIA MUNICIPAL DE SAÚDE DE FORTALEZA - BREVE APRESENTAÇÃO}

O programa de RMFC da SMSF teve início em março de 2006. Participam do curso 77 médicos residentes (50 residentes 
de primeiro ano e 27 de segundo). O objetivo principal desse programa é formar médicos com as competências necessárias para atuar na especialidade de Medicina de Família na rede municipal de saúde de Fortaleza, compondo as equipes de Saúde da Família e, consequentemente, aumentar a resolubilidade dos serviços de atenção básica, possibilitando, ao mesmo tempo, a criação de espaços de práticas concretos e qualificados de formação de pessoal. O programa foi criado com uma proposta de duração de dois anos, prevendo atividades teóricas e práticas realizadas em serviço (unidades básicas de saúde) e na comunidade (visita domiciliar). As atividades de treinamento ocorrem num contexto complexo de interações de preceptores, residentes, profissionais de áreas diversas do conhecimento (enfermeiros, odontólogos, assistentes sociais, auxiliares de enfermagem, agentes comunitários de saúde), pacientes, comunidade e instituições.

Todas as atividades práticas são supervisionadas diretamente por preceptores, que são médicos especialistas - pediatras, gineco-obstetras, clínicos gerais, psiquiatras e médicos de família - da rede de atenção à saúde da SMSF. As aulas teóricas são ministradas por professores das universidades parceiras da Secretaria Municipal de Saúde.

A concepção de formar profissionais com uma visão de vigilância à saúde e que prestem uma atenção integral à população, com um olhar no indivíduo e em seu contexto social, já se encontra contemplada nos projetos político-pedagógicos dos cursos de graduação na área da saúde, porém precisa ser efetivada em ações como as propostas aqui, pelo programa do curso de RMFC.

\section{METODOLOGIA}

\section{Tipo e natureza do estudo}

A pesquisa realizada adotou o desenho de estudo de caso, com abordagem qualitativa. Na área da educação, esse tipo de pesquisa firmou-se como abordagem promissora de investigação. No que concerne à avaliação educacional, o emprego de abordagens qualitativas têm sua base, segundo Minayo9, "na crença de que os programas sociais tendem a desenvolver suas metas à medida que estão em andamento, o que torna difícil conhecer seus benefícios, avaliando-os apenas a partir de procedimentos fixos e de metas inalteráveis". Em se tratando de um estudo de caso, Gonçalves ${ }^{10}$ sustenta que "no geral, o estudo de caso, ao realizar um estudo minucioso de uma experiência, objetiva colaborar na tomada de decisões sobre o problema estudado, indicando as possibilidades para sua modificação". Em consonância com os autores mencionados, consideramos que esta abordagem poderia trazer subsídios para a avaliação do curso, propósito último desta pesquisa.

\section{Sujeitos do estudo}

Dos 27 alunos/residentes que ingressaram no programa de RMFC da SMSF em março de 2006 e que atualmente cursam o segundo ano, 20 aceitaram voluntariamente participar da pesquisa. Entendemos que os alunos, tendo cumprido cerca de $50 \%$ da carga horária teórica e prática do curso, se encontravam em condições de refletir sobre aspectos referentes ao curso e poderiam contribuir para o seu aprimoramento. Seus depoimentos foram identificados pela letra $R$, acompanhada de um número, significando o residente 1, 2, 3 até o residente de número 20.

\section{Instrumento utilizado}

O instrumento de coleta de dados escolhido foi um questionário (roteiro interrogativo) com 13 questões abertas, o que possibilitou aos respondentes ficarem livres para usar as próprias palavras, sem se limitarem ao preenchimento de opções previamente estabelecidas ${ }^{11}$. Entre as vantagens do uso de questões abertas está o fato de que elas podem proporcionar mais informações, explicações e esclarecimentos significativos por parte dos respondentes sobre os temas abordados. O anonimato dos respondentes foi assegurado, garantindo que a informação fornecida seria tratada confidencialmente.

Todas as questões contidas no instrumento de coleta de dados foram direcionadas para os seguintes itens, que contemplam os interesses da avaliação:

- processo pedagógico (métodos, técnicas e procedimentos para ensinar);

- ganhos obtidos em conhecimentos, habilidades e atitudes (competências) para os profissionais atuarem como médicos de família;

- suporte técnico proporcionado pelos preceptores nas sessões de prática;

- motivações para ingressarem no curso;

- condições de infraestrutura de ensino.

Os dados foram coletados em abril de 2007, após um ano do ingresso dos residentes nas unidades básicas de Saúde da Família, em Fortaleza, campo de ensino e serviço. A pesquisa que originou o artigo aqui proposto foi apresentada como dissertação de mestrado e aprovada pelo Comitê de Ética em pesquisa da Universidade Estadual do Ceará, sob o processo de número 06504372-3 em abril de 2007.

\section{Análise dos dados}

O material colhido a partir das respostas ao questionário foi processado por meio do emprego da técnica de análise de conteúdo, de Bardin, modalidade temática. Na origem, 
a "análise de conteúdo" foi usada em estudos no campo da comunicação, para identificar conteúdos subliminares às falas ou textos. Contudo, o uso da técnica é vasto, e o próprio autor advoga sua adequação à avaliação de formações por meio de instrumentos de roteiros interrogativos semiestruturados. Esta técnica consiste em descobrir os "núcleos de sentido" que compõem a comunicação e cuja presença, ou frequência de aparição, pode significar alguma coisa para o objetivo analítico escolhido $^{12}$. Desse modo, foram seguidas as orientações metodológicas preconizadas por Bardin, e as categorias de análise foram construídas com base nas questões norteadoras contidas no roteiro interrogativo apresentado aos alunos/residentes.

As respostas foram agrupadas enfatizando o número de vezes em que a mesma ideia se repetia, contextualizando-se os significados. Lamentavelmente, como o questionário foi entregue aos alunos para preenchimento individual, isto impossibilitou a exploração das opiniões fornecidas, resultando numa certa limitação em termos de aprofundamento das questões, pois as respostas obtidas foram bastante "econômicas". Isto levou à quantificação das recorrências de pontos de vista, limitada às categorias previamente estabelecidas, uma vez que não foram encontradas, no conjunto dos depoimentos por temas, outras categorias (espontâneas) que permitissem ampliar o leque de associações de ideias, conforme preconiza o método de Bardin.

Com base nesta compreensão, foram elaboradas 11 categorias: 1) adequação das aulas; 2) estruturação das aulas teóricas; 3) contextualização dos conteúdos; 4) interações de professores e/ou preceptores e alunos/residentes; 5) mudanças de atitudes; 6) sistemas de informação que embasam o planejamento de ações; 7) atividades de Educação em Saúde; 8) lacunas na formação; 9) utilização de recursos audiovisuais e material institucional; 10) didática de ensino; 11) motivação.

\section{Resultados do estudo por categoria identificada}

\section{Adequação das aulas}

Perguntou-se aos alunos se as aulas teóricas eram apropriadas ao desenvolvimento da competência para exercer de forma crítica a função de médico de família em equipe multiprofissional no contexto do SUS.

Os alunos se dividiram a respeito da questão: $55 \%$ das respostas sinalizaram que o conteúdo das aulas teóricas estaria adequado ao desenvolvimento de habilidades clínicas individuais para a atenção aos pacientes (usuários do sistema); as aulas seriam deficientes em conteúdos de abordagem familiar e saúde coletiva, conhecimentos fundamentais para um médico de família desenvolver a referida competência, como se constata na resposta a seguir: "em termos de conhecimentos nas áreas clínicas básicas foi suficiente, mas há falha em conteúdos que contemplem a abordagem familiar e de saúde coletiva" (R. 2).

No restante das respostas (45\%), destaca-se a compreensão de que as aulas estariam adequadas ao que se propõem, conforme mostra um dos depoimentos: "as aulas teóricas, em sua grande maioria, são úteis e compatíveis ao desenvolvimento adequado da competência do médico de família" (R. 7).

\section{Estruturação das aulas teóricas}

Perguntou-se aos alunos se as aulas apresentadas por ciclo de vida - saúde da mulher, da criança, do adulto, do idoso -, sem necessariamente uma sequência que esgote um ciclo, propiciam uma aprendizagem satisfatória.

A disposição das aulas, como proposta no curso, foi mencionada como facilitadora da aprendizagem em 50\% das respostas. As restantes expressaram que as aulas deveriam ser dadas por módulos que esgotassem totalmente um ciclo de vida, e não intercalando aulas sobre os vários ciclos. As respostas seguintes demonstram esse ponto de vista: "a divisão das aulas teóricas por ciclos de vida é interessante, mas deveria ser organizada por grandes módulos para dar continuidade aos assuntos..." (R. 10); "esta metodologia dificulta um pouco o aprendizado e a cronologia dos assuntos, pois cada dia é sobre um assunto de ciclo de vida diferente" (R. 3).

\section{Contextualização dos conteúdos}

É importante avaliar se os conteúdos ministrados no curso estão contextualizados na rotina de trabalho dos residentes, porque isto assegura que o aluno aplique tais conhecimentos na atenção aos pacientes sob sua responsabilidade, nas unidades de saúde. Assim, perguntou-se aos residentes se eles acham que as aulas estão contextualizadas segundo a realidade em que atuam. Foi consenso entre os residentes (quase $100 \%$ das respostas) a ideia de que os temas abordados estavam adequados à sua prática diária. No entanto, um significativo número de depoimentos (35\%) expressou a necessidade de elaborar protocolos clínicos para a normatização de condutas. Destacamos duas respostas que expressam esses julgamentos: "sim, os conteúdos das aulas têm um cunho bem prático... no entanto, seria importante que pudéssemos construir juntos com os professores um protocolo, de forma a sistematizar o fluxograma de atendimento" (R. 5); "sim, mas, como sugestão, poderiam ser construídos consensos/rotinas dos problemas mais comuns" (R. 10).

Sem desvalorizar a importância dos conteúdos para uma boa formação, alguns depoimentos revelam que a dificulda- 
de de acesso dos pacientes a exames laboratoriais e medicamentos na atenção básica prejudica a efetividade da prática com os pacientes, pois dificulta a aplicação dos conhecimentos adquiridos no curso. A descrição a seguir demonstra essa insatisfação: "a falta de alguns elementos nos impede de fazer um melhor trabalho... falta de exames básicos e demora nos resultados..." (R. 8)

\section{Interações de professores elou preceptores e alunos/ residentes}

A fim de se avaliar como ocorre a interação dos residentes com os professores na sala de aula, e com os preceptores (professores de prática) nas sessões na unidade de saúde, perguntou-se como tal interação está sendo percebida.

As interações na sala de aula (professor/aluno-residente) são vistas como satisfatórias, segundo mais da metade das respostas. Entretanto, cerca de um terço destas ressalta que a aula mais expositiva não favorece a interação, tanto quanto uma aula baseada em situações-problema, conforme se constata nas descrições a seguir: "existem aulas em que não existe interação, pois somos meros espectadores" (R. 2); "alguns professores têm metodologias que facilitam a interação com os alunos... às vezes abordam assuntos muito extensos e isso dificulta a interação" (R. 6).

Quanto à interação dos residentes com o preceptor de prática nas unidades de saúde, a maioria das respostas revela que os alunos consideram que este relacionamento está sendo efetivo para o processo de aprendizagem, apesar de alguns depoimentos apontarem falta de habilidades pedagógicas por parte de alguns preceptores, como demonstra a resposta a seguir: "o problema é que alguns preceptores não têm habilidade pedagógica adequada" (R. 18).

\section{Mudanças de atitudes}

Para melhor compreender se os residentes perceberam mudanças de atitude na sua relação com a comunidade a partir dos conhecimentos adquiridos no curso, perguntou-se como eles veem esse processo.

Contraditoriamente às respostas dadas à primeira categoria de análise (adequação das aulas), 75\% das respostas indicaram que os conhecimentos teóricos e práticos até aqui abordados possibilitaram que os alunos refletissem sobre a importância do contexto familiar na atenção às doenças, fortalecendo vínculos com a comunidade. Como também mencionaram estar atendendo a população com maior segurança, é possível que os alunos estejam se referindo apenas aos conhecimentos clínicos e habilidades (Ginecologia, Obstetrícia, Pediatria, etc.) adquiridos no curso. Dois relatos a seguir expressam essa opinião: "fortaleceu mais o vínculo, compromisso com a comunidade" (R. 17); "houve uma grande mudança... agora já me sinto mais seguro devido aos conhecimentos teóricos adquiridos" (R. 7).

\section{Sistemas de informação que embasam o planejamento de ações}

Para avaliar o quanto os residentes estão montando seus planos de intervenção na comunidade a partir dos conhecimentos adquiridos no curso sobre os sistemas de informação, perguntou-se se eles estão utilizando esse conhecimento para planejar as ações. Em dois terços das respostas (75\%), a principal observação foi que os conteúdos repassados sobre o tema informação em saúde não foram suficientemente aprofundados para permitir o desenho de planos de intervenção. A resposta a seguir ilustra essa consideração: "não, infelizmente não houve aprofundamento de como usar o Siab (sistema de informação da atenção básica), como também de como planejar ações prioritárias" (R. 7).

Ainda como parte das considerações feitas pelos residentes sobre essa questão, surgiu outro tema de análise: a dificuldade de viabilizar o acesso às informações do Siab, em virtude da ausência dos agentes comunitários de saúde (ACS) na área de abrangência da unidade, responsáveis diretos pela coleta desses dados, conforme expressa a resposta: "pois, como não há o cadastramento da população da área de abrangência da unidade de saúde por deficiência de ACS, também não há esta informação (dados do Siab) disponível" (R. 13).

\section{Atividades de Educação em Saúde}

Para avaliar o quanto os ensinamentos sobre Educação em Saúde se concretizaram em atividades promotoras de saúde na comunidade assistida pelos residentes, perguntou-se se eles achavam que esses ensinamentos tinham sido suficientes para isto. Mais de um terço das respostas (65\%) indicaram que, até aquele momento, o aprendizado sobre ações de Educação em Saúde estava sendo satisfatório, principalmente nas sessões de prática com os preceptores, conforme se observa na descrição a seguir: "sim, a preceptoria em medicina de família e comunidade vem fornecendo subsídios para exercer a função de educador em saúde e multiplicador de conhecimentos junto à comunidade" (R. 20).

Percebemos, entretanto, que cerca de um terço (35\%) das respostas sugere que os alunos não se achavam capazes de exercer a atividade de Educação em Saúde com base no que já foi abordado no curso, como explicitado na seguinte descrição: "não, muitos temas em Educação em Saúde não foram dados nas aulas e também uma abordagem prática do assunto não foi ministrada" (R. 16). 


\section{Lacunas na formação}

Perguntou-se aos residentes o que achavam que ainda precisava ser abordado no curso ou o que teria ficado deficiente nos conteúdos.

Os aspectos do curso mais citados como lacunas na formação, na opinião dos alunos, foram: necessidade de mais conhecimentos clínicos especializados (25\% das respostas); más condições de infraestrutura das unidades de saúde (25\%); ensino de técnicas de abordagem de grupos (20\%); mais discussão de temas como gestão e planejamento em saúde (15\%); como trabalhar Educação em Saúde (10\%); necessidade de mais turnos de prática com o preceptor especialista em Medicina de Família (15\%). Os depoimentos a seguir ilustram algumas dessas considerações: "falta de oficinas e aulas teórico-práticas sobre ECG (eletrocardiograma), reumatologia, dermatologia..." (R.7); "acho que os conhecimentos básicos de áreas especializadas eram para ser colocados em aulas teóricas (reumatologia, urologia, etc.)" (R. 19); "a dificuldade de formar grupos terapêuticos em minha unidade..." (R. 9).

\section{Utilização de recursos audiovisuais e material instrucional}

A fim de melhor entender qual a parcela de contribuição do uso de recursos audiovisuais e do material instrucional do curso no aproveitamento dos alunos, perguntou-se o que achavam da disponibilidade dessas ferramentas pedagógicas no curso.

No conjunto das respostas sobressai a consideração de que o uso de recursos audiovisuais pelo professor é importante, mas nem sempre o material exposto foi disponibilizado aos alunos e às vezes nem a bibliografia dos temas abordados, o que facilitaria o direcionamento dos estudos a posteriori (90\% das respostas), conforme o relato a seguir: "os recursos audiovisuais são bons... o maior problema visto até hoje foi o fato de as aulas não serem disponibilizadas para todos os residentes..." (R. 3).

\section{Didática de ensino}

Avaliar como os residentes percebem os métodos e as técnicas que os professores utilizam durante as aulas teóricas em sala de aula foi outro tema focalizado neste estudo e muito articulado à categoria analisada anteriormente.

Mais da metade das respostas obtidas aponta como bom o desempenho didático dos professores. Em seis delas, porém, transparece a queixa de que as aulas deveriam ser mais "práticas", simular situações reais e não somente expor conteúdos teóricos: "cerca de 70\% dos professores têm bom desempenho pedagógico, só faltando mais exercícios que simulem situa- ções reais sobre o tema abordado" (R.11); "alguns professores utilizam nas aulas casos clínicos que são bem mais interessantes para o aprendizado" (R.6).

\section{Motivação}

Com esta última categoria procuramos entender que fatores influenciaram os residentes a escolher a Medicina de Família como especialidade, perguntando o que mais os motivou a ingressar nesse curso.

A necessidade de aperfeiçoamento técnico foi a razão mais apontada para ingressar na residência (75\% das respostas), como exemplificado neste relato: "o primeiro fator foi melhorar minha capacitação para ser MFC (médico de família e comunidade), acreditando que só um programa acadêmico dentro do sistema de saúde poderia melhorar a atenção à saúde proporcionada à população" (R. 5).

Alguns dos residentes que relataram a necessidade de aperfeiçoamento atrelaram a isto o fato de terem passado no concurso público promovido pela SMSF para ocupar o cargo de médico do PFS, conforme ilustrado a seguir: "o fato de ter sido aprovado no concurso do PSF-Fortaleza, me fez buscar capacitação" (R. 20).

\section{DISCUSSÃO}

$\mathrm{O}$ fato de alguns residentes considerarem as aulas deficientes em conteúdos na abordagem familiar sugere duas possibilidades de interpretação: primeiramente, além de quererem aulas de temas que contemplem as clínicas básicas, os alunos acham necessário também adquirir conhecimentos sobre as ferramentas de abordagem familiar e de saúde coletiva, e, na opinião deles, a falta de mais conteúdos nessa área teria sido uma falha do curso; outra possibilidade a considerar é que os alunos podem estar se referindo ao fato de alguns professores ministrarem aulas que contemplam apenas o manejo clínico de doenças sem levar em conta o contexto mais abrangente da família inserida numa comunidade, relacionando ações individuais com ações de saúde coletiva, segundo o conceito de clínica ampliada, que é "considerar que o objeto de trabalho da assistência à saúde é uma pessoa, ou um grupo, ou uma família, ou um coletivo institucional com doença ou risco de adoecer"13 $^{\prime \prime}$. Esta condição poderia ser explicada pela formação médica de especialista clínico da maioria dos professores. Em relação aos outros residentes, que afirmam não haver problemas com os conteúdos das aulas, talvez estes já tenham uma experiência anterior nessa área e por isso não sintam essa deficiência. Independentemente do que os alunos quiseram expressar com seus depoimentos, a experiência na formação de profissionais para o atendimento na medicina de família 
nos leva a ponderar que a "clínica ampliada" deveria merecer maior atenção da coordenação deste tipo de curso, pelos argumentos acima apontados.

Na formação de médicos de família, é importante a abordagem de temas que propiciem condições para que estes profissionais reflitam sobre o seu trabalho na atenção básica dentro dos princípios da ESF. Nesse contexto, Zabala ${ }^{14}$ considera que uma questão fundamental na prática educativa é avaliar se o que está sendo discutido em sala de aula é condizente com o que se pretende em relação aos objetivos educacionais, e se as atividades didáticas propostas são suficientes e necessárias para alcançar os objetivos propostos.

A proposta do curso de dispor as aulas intercalando os diversos ciclos de vida em detrimento de módulos que esgotassem totalmente cada ciclo foi vista como um fator que dificulta uma percepção mais abrangente dos problemas (a clínica ampliada). Nesta direção, Andrade ${ }^{13}$ sustenta que o médico de família precisa trabalhar com uma nova visão em relação à doença, baseada no conceito de "clínica ampliada" há pouco citado. Uma das tarefas do professor no curso de RMFC é, portanto, proporcionar atividades em sala de aula que permitam ao aluno refletir sobre essa mudança de atitude perante o processo saúde-doença nas diferentes etapas de vida das pessoas. É provável, entretanto, que aulas que intercalem a abordagem de temas por ciclo de vida possam deixar uma sensação de fragmentação de problemas e não consigam passar ao aluno uma visão holística da atenção, tão importante para a mudança do paradigma do atendimento centrado na doença, para a atenção no indivíduo, no âmbito familiar. Podemos pressupor também que os conteúdos, quando separados didaticamente, dificultam sua articulação num continuum, ou ciclo permanente.

Foi bastante positivo o fato de a maioria dos residentes relatar que os conteúdos abordados são condizentes com a realidade da prática diária deles nas unidades básicas de saúde. Nesse sentido, Vasconcellos ${ }^{15}$ relata que a disponibilidade de aulas cujo conteúdo seja articulado com a realidade vivida pelo aluno é um fator importante para obter uma aprendizagem significativa. O autor ainda afirma que, para se conseguir uma educação significativa, "a educação, o conteúdo, devem estar ligados à realidade do educando"15.

A queixa sobre a falta da elaboração de protocolos clínicos deveria ser considerada pela coordenação do curso, visto que hoje, na medicina em geral, a utilização de protocolos nos atendimentos ambulatoriais e hospitalares é uma prática muito comum e facilita a tomada de condutas diante dos pacientes.

Dos depoimentos relativos à dificuldade de acesso dos pacientes a exames laboratoriais e medicamentos na atenção básica, prejudicando o trabalho dos residentes e dificultando a aplicação dos conhecimentos adquiridos no curso, podemos inferir que os residentes estão se dando conta de que outros elementos influenciam no processo de trabalho. Neste sentido, Rodrigues e Araújo ${ }^{16}$ indicam que no processo de trabalho em saúde há uma divisão que compreende três dimensões. Numa delas, a da produção de serviços, viabilizam-se as ações de promoção, prevenção e cura sobre as demandas de saúde da população. Mas, para que essa prática seja bem-sucedida, é importante a boa relação interpessoal dos usuários com os profissionais, possibilitando a criação de vínculos entre eles, o trabalho em equipe e os elementos estruturais dos serviços (equipamentos, insumos, estrutura física da unidade), fundamentais ao exercício profissional na medicina, podendo interferir positiva ou negativamente nas ações terapêuticas. A estrutura global dos serviços de saúde - campo de ensino e trabalho dos residentes - deveria estar adequada para possibilitar a aprendizagem e/ou o exercício de uma prática com um mínimo de qualidade para um atendimento à comunidade. Não se cogita uma estrutura ideal, porém concordamos em que são necessárias condições mínimas de trabalho nas unidades de saúde, de forma a possibilitar um atendimento com ética, segurança e humanização.

Quanto às interações entre professor e aluno em sala de aula, os que sustentam que as aulas deveriam ser elaboradas com base em situações-problema, favorecendo maior interação, estão reivindicando que se adote a concepção construtivista de aprendizagem, proposta pelo curso. Nela, "ensinar envolve estabelecer uma série de relações que devem conduzir à elaboração, por parte do aprendiz, de representações pessoais baseadas em experimentação, reflexão, síntese sobre o conteúdo objeto de aprendizagem"14. A falta de professores que trabalhem nessa linha pode explicar esta situação de aulas mais expositivas, das quais o aluno pouco participa. Isto reflete, de alguma forma, certa distância entre a proposta pedagógica e a realidade das condições da formação.

Segundo Zabala ${ }^{14}$, "a chave de todo ensino são as relações que se estabelecem entre os professores, os alunos e os conteúdos de aprendizagem". Nessa lógica, a compreensão do autor leva ao entendimento de que a aula deve ser organizada de maneira a favorecer interações em diferentes níveis (em relação ao grupo-classe ou aos grupos de alunos, interações individuais ou outras), dependendo da atividade proposta pelo professor num dado momento da aula.

No caso dos preceptores de prática nas unidades, segundo os depoimentos favoráveis da maioria dos alunos, o curso está alcançando seu objetivo em relação a esse momento de aprendizagem. O preceptor é um profissional que desenvolve- 
rá um trabalho de natureza pedagógica nesse curso, sendo um facilitador da aprendizagem. Ele acompanha os residentes no desenvolvimento de competências. Ele tem a função de ajudar o residente a alcançar seus objetivos. No caso dos depoimentos dos cinco alunos que se queixaram da falta de habilidades pedagógicas de alguns preceptores, é possível que estes profissionais (médicos da rede ambulatorial da secretaria de saúde) realmente não tenham a requerida formação pedagógica, o que pode dificultar essa interação com o aluno no momento do ato de ensinar.

O fortalecimento de vínculos com a comunidade e maior segurança no atendimento à população - com a ampliação do olhar clínico do médico para o indivíduo, dentro do contexto familiar, e não somente para a doença - são qualidades importantes no médico de família. Estas mudanças de atitude que, segundo os depoimentos, os residentes adquiriram após o ingresso no curso é fato bastante positivo na avaliação dessa residência.

Segundo Edgar Morin ${ }^{17}$, o conhecimento, para que seja realmente um indutor de transformação, precisa ser "pertinente", ou seja, deve ser contextualizado para que adquira sentido; global, não fragmentado, as partes existem como tal, mas não podem ser apresentadas separadas do todo; deve reconhecer o caráter multidimensional do ser humano e enfrentar a complexidade, que, segundo ele, é "a união entre a unidade e a multiplicidade". Nesse sentido, é bastante positiva a avaliação que fazem os residentes em termos de que o curso proporciona a construção de novos conhecimentos, como também a criação de vínculos com a comunidade, pois a Medicina de Família tem papel relevante no reconhecimento do que representa a família e qual sua influência no estado de saúde de seus componentes.

Segundo os residentes, o aprendizado insatisfatório em relação aos sistemas de informação da atenção básica é uma lacuna importante num curso de residência de Medicina de Família. Tal constatação pode dificultar o entendimento, por parte dos alunos, de que, na qualidade de médicos de família, eles são responsáveis pela vigilância epidemiológica dos territórios sob sua responsabilidade. A informação em saúde é o elemento-chave para o planejamento de ações individuais e coletivas na comunidade. É a representação de uma realidade. $\mathrm{Na}$ atenção básica, campo privilegiado de atuação do médico de família, conhecer o Siab é uma prioridade para a formação desses médicos, pois este sistema é potencialmente uma fonte de dados para realizar o diagnóstico de saúde de uma área e acompanhar as atividades das equipes de Saúde da Família, norteando o planejamento e avaliação de ações de saúde propostas para aquela realidade ${ }^{18}$. $\mathrm{O}$ fato - enfatizado por alguns residentes - de que a ausência do agente comunitário de saúde na área dificultava o acesso às informações do Siab reforça a importância da tomada de consciência, pelos residentes, da participação dos outros profissionais (no caso os ACS) que compõem a equipe de saúde da família no atendimento à população usuária do sistema, na concretização de um trabalho interdisciplinar.

Em relação às atividades de Educação em Saúde, uma prática que deve fazer parte da rotina diária de um médico de família, não foi consenso entre os residentes que esse tema tenha sido abordado com a devida ênfase no curso. Provavelmente, a falta de familiaridade dos professores, que não labutam na atenção básica, e de alguns preceptores (mais especialistas clínicos) com essa ação no cotidiano de trabalho contribuiu para esta constatação.

Quanto às lacunas que necessitam ser preenchidas no curso na opinião dos alunos, cada um identifica no curso uma deficiência específica em determinadas áreas de conhecimento e também em outros fatores que interferem no aprendizado. Os relatos parecem demonstrar que tais deficiências decorrem de dificuldades pessoais da formação acadêmica desses alunos. Outras, mais gerais, identificadas por eles, podem ser vinculadas ao curso, como a proposta de formação de médicos de família (abordagem familiar e de grupo, Educação em Saúde, gestão, preceptoria de Medicina de Família). Fica a recomendação à coordenação para supri-las. Nessa perspectiva, o pensamento de Gil ${ }^{19}$ ratifica essa recomendação, quando o autor afirma que é muito importante, ao se elaborar um plano de ensino, definir bem os conteúdos e que um dos critérios para selecioná-los é vinculá-los aos objetivos do curso. No caso da RMFC de Fortaleza, objeto desse estudo, todos os temas abordados em sala de aula ou nas sessões de prática nas unidades de saúde deveriam estar de acordo com as competências (objetivos educacionais) requeridas a um médico de família e comunidade, uma vez que estas estão inseridas no planejamento curricular do curso.

Nas respostas dos residentes, há uma preocupação salutar em adquirir, por meio desse curso, todos os conhecimentos necessários à competência de exercer com qualidade a Medicina de Família, o que parece sugerir que estão fazendo uma autorreflexão sobre aonde estão conseguindo chegar até esse momento em termos de competências adquiridas. Esta é uma reflexão necessária e importante não só para o curso, mas, sobretudo, para o próprio residente, que, ao avaliar os ganhos em termos de aprendizagem, se reconduz inserido nesse mesmo processo.

No que diz respeito à opinião dos residentes sobre os recursos audiovisuais como importante ferramenta pedagógica 
do professor para facilitar a comunicação docente, Bordenave e Pereira ${ }^{20}$ alertam sobre o fato de que o professor deve utilizar "um esquema pedagógico que permita selecionar e utilizar os meios multissensoriais mais adequados para cada etapa do processo de ensino". Em relação ao fato de algumas aulas não serem disponibilizadas aos alunos, pressupõe-se que falte organização no curso quanto a esse ponto.

O fato de grande parte dos alunos ter considerado a didática (métodos e técnicas utilizados pelos professores em sala de aula) boa é um ponto positivo do curso. No entanto, $30 \%$ das respostas questionam as técnicas utilizadas na abordagem dos conteúdos, insistindo em aulas que simulem situações reais da vivência prática dos alunos.

De acordo com Bordenave e Pereira ${ }^{20}$, um dos pressupostos que deve guiar o professor quando da seleção de atividades de ensino-aprendizagem "é que os objetivos educacionais determinam os tipos de atividades". No curso em questão, que propõe como metodologia de ensino-aprendizagem a problematização, as atividades teóricas e práticas deveriam utilizar situações da realidade vivida pelos alunos como cenário de aprendizagem, contemplando os objetivos educacionais, conforme sugerem os autores.

Supomos que as opiniões dos residentes sobre a metodologia de ensino proposta pelos professores decorram do fato de que boa parte destes é de médicos especialistas que, por não atuarem na atenção básica, talvez tenham dificuldade de expor os assuntos de maneira mais relacionada com os limites de atuação do médico de família.

O fato de a necessidade de qualificação na área da Medicina de Família ter sido o que motivou a quase totalidade dos alunos a ingressar no curso confirma os trabalhos de Amoret$\mathrm{ti}^{4}$, Feuerwerker ${ }^{21}$ e Machado ${ }^{5}$, que mostram que os cursos de graduação em Medicina não preparam um profissional com perfil para atuar na ESF.

Os relatos dos sujeitos demonstram um senso de responsabilidade bastante pertinente para com a saúde da população. Os alunos admitem suas limitações para lidar com pacientes/usuários no contexto da Medicina Familiar e buscam superar tal dificuldade com uma pós-graduação, a residência médica, já que terão que ocupar o cargo de médico do PSF da Secretaria de Saúde de Fortaleza e não receberam formação acadêmica para atuar na realidade dos serviços de atenção básica de saúde.

\section{CONCLUSÕES}

À luz dos dados, é inegável a contribuição que o curso de RMFC da SMSF proporciona à formação desses profissionais, contribuindo com o processo de qualificação tão necessário aos profissionais que atuam na ESF, no contexto do SUS. Pelos relatos dos residentes, sujeitos do estudo, o curso realmente faz uma diferença na aquisição de novos conhecimentos, ainda que sejam necessários alguns ajustes ou adequações no conteúdo do programa, na seleção e/ou educação permanente dos preceptores e nas condições de aprendizagem nas unidades de saúde.

Acreditamos que o contato do profissional com a realidade das unidades de saúde poderá contribuir para seu amadurecimento em termos de propostas para superar as dificuldades encontradas, pois ao final do curso ele trabalhará com essa mesma realidade.

Entendemos que esse processo de avaliação deve ser contínuo, e seus resultados, somados e confrontados com os de outras dimensões avaliativas, com o intuito de colher subsídios para o aprimoramento do curso.

\section{REFERÊNCIAS}

1. Pelliano AM. Programa de saúde da família. Seminário de experiências internacionais em saúde da família, Brasília; 1999. Relatório Final.

2. Brasil. Departamento de Atenção Básica [homepage da Internet]. [acesso em: 03 out. 2007]. Disponível em: http:// www.saude.gov.br//dab/atençãobasica.php.

3. Brasil. Ministério da Saúde. Secretaria Executiva. Programa Saúde da Família. - Brasília: MS; 2001.

4. Amoretti R. A educação médica diante das necessidades sociais em saúde. Rev Bras Educ Med. 2005; 29: (2):136 -146.

5. Machado MH. (Coord.). Perfil dos médicos e enfermeiros do PSF no Brasil e grandes regiões: Relatório final. Brasília: Ministério da Saúde, 2000.

6. Gualberto LD. Residência médica no Brasil: avaliação atual dos principais programas credenciados pelo MEC, Med online. 1998; 1: (1).

7. Mendes OM. Avaliação formativa no ensino superior: reflexões e alternativas possíveis. In: Passos I, Veiga A, Lomônaco MPN (Org.). Currículo e avaliação na educação superior. São Paulo: Junqueira\&Marin; 2005.

8. Rodrigues MSS. Auto-avaliação e planejamento participativos no âmbito da Universidade Federal do Ceará: em busca de saberes e da mudança de cultura institucional. Fortaleza; 2007. Doutorado [Tese] - Universidade Federal do Ceará.

9. Minayo MCS, Assis SG, Souza RE. Avaliação por triangulação de métodos: abordagens de programas sócias. Rio de Janeiro: Fiocruz; 2005.

10. Gonçalves EP. Conversas sobre Iniciação à pesquisa cientifica. Campinas: Alínea; 2005. 
11. Chagas AATR. O questionário na pesquisa científica. Rev adm on line [periódico na internet]. 2000; (1): 1. [acesso em 27 set. 2006]. Disponível em: http://www.fecap.br/adm_ online/art11/anival.htm.

12. Bardin L. Análise de conteúdo. Lisboa: Persona; 1977.

13. Andrade LOM, Barreto ICHC, Bezerra RC. Atenção primária à saúde e estratégia saúde da família. In: Campos GWS et al. (Org.). Tratado de Saúde Coletiva. São Paulo: Hucitec; 2006. p. 786-787.

14. Zabala A. A prática educativa: como ensinar. Porto Alegre: Artmed; 1998.

15. Vasconcelos CS. Construção do conhecimento em sala de aula. São Paulo: Libertad; 2002.

16. Rodrigues PM, Araújo MSS. O processo de trabalho em saúde da família. [acesso em 10 ago. 2007]. Disponível em: http://www.ufrn.br/davinci/abril/capa.htm.

17. Morin E. Os sete saberes necessários à educação do futuro. São Paulo: Cortez; 2006.

18. Gil AC. Metodologia do ensino superior. São Paulo: Atlas; 2005.

19. Bordenave JD, Pereira AM. Estratégias de ensino-aprendizagem. Petrópolis: Vozes; 2004.
21. Feuerwerker LCM. A formação de médicos especialistas e a residência médica no Brasil. Saúde Debate. 2001; (25): 39-54.

\section{CONTRIBUÇÃO DOS AUTORES}

Verônica Said de Castro: busca de dados, organização e análise dos dados e elaboração inicial do artigo. Silvia Maria Nóbrega-Therrien: contribuição na busca de dados, orientação na organização e na análise dos dados e leitura e re-elaboração do artigo.

\section{CONFLITO DE INTERESSES}

Declarou não haver

\section{ENDEREÇO PARA CORRESPONDÊNCIA}

Verônica S. de Castro

Sistema Municipal de Saúde Escola da Secretaria

Municipal de Saúde de Fortaleza

Rua do Rosário, 283, 5ํandar

Centro - Fortaleza

CEP: 60055-090 - CE

E-mail: veronicasaid@uol.com.br 